\title{
Suicidal Behaviors Among Ukrainian College Students: the Role of Substance Use, Religion, and Depression
}

\section{Viktor Burlaka ${ }^{1}$ (D) Jun Sung Hong ${ }^{1} \cdot$ Oleksii Serdiuk $^{2} \cdot$ Liudmyla Krupelnytska $^{3}$ • Svitlana Paschenko ${ }^{3}$ - Nariman Darvishov ${ }^{3}$. Iuliia Churakova ${ }^{4}$}

Published online: 02 June 2020

(C) Springer Science+Business Media, LLC, part of Springer Nature 2020

\begin{abstract}
Early adulthood is a critical life period associated with increased suicide risk. The present study used a sample of students from ten Ukrainian public universities $(N=1005)$. Participants were 17 to 24 years of age $(M=19.19, \mathrm{SD}=1.99)$. The prevalence of lifetime suicidal ideation was $26.13 \%$ and $5.45 \%$ of participants reported a lifetime suicide attempt. Participants were more likely to report higher lifetime suicidal ideation if they had higher rates of alcohol and marijuana use, have met a clinical cutoff point for depression and were older, females, and not affiliated with any religion. The lifetime suicide attempt was associated with clinical levels of depression, increased marijuana use, and non-religious affiliation. These results suggest that mental health, alcohol and cannabis use can increase the risk of suicidality while religious affiliation might be an important protective mechanism for Ukrainian young adults at risk for suicidal behaviors.
\end{abstract}

Keywords Substance use $\cdot$ College students $\cdot$ Mental health $\cdot$ Religiosity $\cdot$ Suicidality $\cdot$ Ukraine

Suicide is one of the leading causes of death among late adolescents and young adults (World Health Organization [WHO] 2019). As many as $12.1 \%$ reported suicide ideation, and $4.1 \%$ had attempted suicide sometime during their life among U.S. adolescents (Nock et al. 2013). Bromet et al. (2007) reported an 8.2\% lifetime prevalence of suicide ideation and 1-1.8\% attempt using WHO data collected 18 years ago (2002) in Ukraine. Although suicide is recognized as one of the leading causes of death in the U.S. (Centers for Disease Control

Viktor Burlaka

viktor@wayne.edu

1 Wayne State University School of School of Social Work, 5447 Woodward Ave, Detroit, MI 48202, USA

2 Kharkiv National University of Internal Affairs Research Lab on Crime Enforcement, Kharkiv, Ukraine

3 Taras Shevchenko National University of Kyiv, Kyiv, Ukraine

4 Wayne State University College of Education, Detroit, MI 48202, USA 
and Prevention 2019). Among U.S. college students, the reported rate of suicide ideation during the past 4 weeks was $2 \%$ (Eisenberg et al. 2007) while the lifetime suicidal ideation was reported by $29.1 \%$ and attempt by $7.6 \%$ of students (Burlaka et al. in press). In Ukraine, with an estimated 22.4 suicide deaths per 100,000 population, the combined rate of suicide for males and females is the fifth highest in the European region (WHO 2016b). According to the WHO data, an estimated 34.5 Ukrainian males per 100,000 population (seventh-highest rate of suicide among males in the world) died by suicide in 2016 (WHO 2016a). An official Ukrainian government source (UkrStat 2017) estimated that 17.4 deaths per 100,000 population involved "purposeful self-harm", and the additional 13.6 deaths per 100,000 population involved "harm with unknown intent" in 2017 (p. 41). Ukraine remains to be a country where suicide rates are among the highest in the world, and preventing suicidal behaviors is more important than ever. Even though the rates of suicide completion in Ukraine are reported by the WHO and the Ukrainian government, the prevalence of suicidal ideation and attempts among college students remains unknown. Understanding the prevalence and factors associated with suicidal ideation and attempts is crucial for the development of effective suicide prevention and intervention programs for young people in Ukraine.

People who have faced considerable loss and traumatic experiences commonly develop a sense of hopelessness and suicidal behaviors (Joiner and Rudd 2005; Kovacs and Garrison 1985). Many Ukrainian families have been deeply affected by historical and ongoing traumas and experienced limited opportunities to utilize their culture and language, revolutions, wars, Holodomor, collapse of the USSR and the subsequent crisis of the 1990s, political turmoil, and the current military conflict in Eastern regions (Burlaka et al. 2018). Also, studies consistently found that the odds of suicidal behaviors were higher among young adults with poor communication and emotion regulation skills (Agarkova 2017), alcohol and drug use (Kokkevi et al. 2012), and psychiatric problems (Borges et al. 2010; Nock et al. 2009). The present study aims to determine the prevalence and the correlates of suicide ideation and attempts in Ukrainian college students.

\section{Substance Use as a Risk Marker for Suicidality}

Substance use appears to be a significant correlate of suicidal thoughts and behaviors, as indicated in several research findings. One study, which examined multiple substance use and self-reported suicide attempts by adolescents in 16 European countries (including Ukraine), found that the odds of reporting a suicide attempt nearly doubled for every additional substance use (Kokkevi et al. 2012). Adolescent mental health is linked to parental coping strategies (Burlaka et al. 2019). In Ukrainian families, higher parental alcohol use, poor family functioning, and exposure to intimate partner violence were associated with the use of negative parenting (Burlaka et al. 2017a), which tended to increase the risk for aggression, rule-breaking behaviors (Burlaka 2016), and alcohol abuse among children (Burlaka 2017). In previous research, young adults' engagement in heavy solitary alcohol use to alleviate negative emotions was linked with higher suicidal ideation (Gonzalez et al. 2009).

A large body of the research literature also demonstrated an association between increased alcohol consumption and self-harming behaviors (Moran et al. 2012) as well as a suicide attempt (McManama O'Brien et al. 2014). In a large U.S. study with 13,069 young adults, aged 18-25, Kim and Burlaka et al. (2018) found that alcohol abuse was 
associated with suicide ideation and attempt. Moreover, among adolescents in Southern Ukraine, higher use of psychoactive substances was found to correlate with increased risk for suicidal behaviors (Rakhimkulova 2016). Concerning suicide completion, Bacherikov et al. (2007) examined autopsy reports in Eastern Ukraine and reported that blood-alcohol content was found in $39.85 \%$ of the cases of completed suicide. Bacherikov et al. (2012) reported that among clinical patients, men were found to be more likely to attempt suicide by self-poisoning, self-cutting, hanging, and falls from a height than women. Furthermore, the risk of suicide was higher among those with depressive symptoms. However, these observations were based on a small sample of 30 individuals and have not been tested using statistical procedures.

In addition to alcohol use, a limited number of studies reported a positive association between tobacco use and suicidal behavior. For instance, one study with 4.86 million U.S. veterans found a strong association between tobacco use disorder and suicide death (Bohnert et al. 2014). Furthermore, a study conducted with a U.S. National Comorbidity Survey (NCS) sample reported that daily tobacco use and dependence were associated with increased suicidal ideation and plans (Kessler et al. 2009). A study conducted by Bromet et al. (2007) also found that a history of tobacco use was significantly and positively related to a higher risk of suicide plans and attempts among Ukrainian adults.

Several studies have also documented a positive relationship between cannabis use and suicidal behaviors. For example, Carvalho et al. (2019) found that current and lifetime cannabis use predicted suicide attempts in a sample of adolescents from 21 low- and middle-income countries across South America, Africa, and Asia. The increased cannabis use was also found to be correlated with higher suicide risk among young Colombian adults who attended medical and nursing schools (Pereira-Morales et al. 2017). However, cannabis use disorder was not associated with suicide ideation in a U.S. sample of 912 college students (Arria et al. 2009). Similarly, cannabis use was neither statistically associated with suicidal ideation nor suicide attempt in Turkey, a country with an extensive historical, geographic, and cultural relationship with Ukraine (Toprak et al. 2011).

\section{Depression as a Risk Marker for Suicidality}

Depression, which has been linked with the higher substance use in college populations (e.g., Churakova et al. 2020), is another serious risk factor for suicide. In a study with 729 adolescents, Garlow et al. (2008) found that adolescents with suicidal ideation had more symptoms of depression. Similar results were reported by Ribeiro et al. (2018) who conducted a meta-analysis of 166 studies published between 1971 and 2014. These researchers found that a higher level of depression was positively associated with suicide ideation, attempt, and death. The suicidal risk was found to be high among nursing students with elevated depressive symptoms in Spain (Aradilla-Herrero et al. 2014) and in Greece (Melissa-Halikiopoulou et al. 2011) as well as among medical school students in Taiwan (Fan et al. 2012). Likewise, Kholmogorova et al. (2009) reported that Russian students with more symptoms of depression were at a higher risk for suicidality. Piliahina et al.'s (2008) study on Ukrainian patients with single and repeated suicidal attempts also revealed that participants in both groups reported feelings of hopelessness, helplessness, sense of isolation, rejection, and loneliness. Piliahina and Chumak (2014) further reported that participants who attempted to kill themselves tended to have higher depression and anxiety. 


\section{Age and Sex Differences in Suicidality}

Research findings on the age and sex differences in suicidality have been inconsistent. Prior research in Ukraine reported that the onset of suicidal ideation was during adulthood when participants reached on average 31 years of age (Bromet et al. 2007). In contrast, the U.S. data suggest that suicidal behaviors begin to manifest between ages 12 and 17 (Nock et al. 2013). A report by the Centers for Disease Control and Prevention, which presented an overview of suicide mortality in the U.S. from 1999 to 2014, demonstrated that suicide is an increasing trend among adolescents and young adults (Curtin et al. 2016).

In terms of sex differences, the Center for Disease Control and Prevention report indicated that the suicide rate for males increased from 17.8 per 100,000 in 1999 to 20.7 per 100,000 in 2014. Among females, the rate increased from 4.0 per 100,000 in 1999 to 5.8 per 100,000 in 2014 (Curtin et al. 2016). Similarly, another study, which included data from 14,738 suicide cases (age group 15-24) in 15 European countries, documented that suicide rates were significantly higher for males (5.5-35.1) than for females (1.3-8.5) (Värnik et al. 2009). Moreover, a study in South Korea, which included suicide rates from 2006 to 2008, also revealed that suicide rate was higher in males than in females; however, the rate was also found to be higher among older people than among younger people (Cheong et al. 2012).

Other research findings indicate that females are more likely to report a higher rate of suicidal behaviors than their male counterparts. According to the U.S. National Comorbidity Survey Replication Adolescent Supplement (NCS-A) finding, suicidal behaviors are more common among females (Nock et al. 2013). Similarly, Kim and Burlaka's (2018) study found that women, aged 18-25, were more likely to engage in suicidal behaviors. Furthermore, one research review of sex differences in the rates of adolescent suicidal behavior among four major ethnic groups in the U.S. (African Americans, Native Americans, Asian Americans, and Latino Americans) showed that females are more likely than males to report suicidal ideation and attempts across all four groups (Langhinrichsen-Rohling et al. 2009)

\section{Religious Affiliation as a Protective Factor}

A considerable body of empirical literature explored the protective nature of religious affiliation against suicidal behaviors across major world religions (Norko et al. 2017). Dervic et al. (2004) found that inpatient study participants with depression who were affiliated with Catholicism, Protestantism, Judaism, or another religion were more likely to view suicide as morally objectionable. These study participants had a lower frequency of lifetime suicide ideation and attempts and had fewer relatives who committed suicides than participants without a religious affiliation (Dervic et al. 2004). For Christians who view suicide as a sin, religious service attendance at least once per week was associated with a five-fold reduction in suicide risk (VanderWeele et al. 2016). In a recent study, U.S. college students who reported higher spirituality were less likely to experience anxiety, depression, and subsequent suicidality (Burlaka et al. in press). Pescosolido (1990), however, argued that the same religious denomination can be a risk or protective factor depending on the socio-cultural environment. To date, no studies have examined the role of religion in suicidal behaviors in Ukraine. 
Based on the previous research literature, the present study hypothesized that participants' higher suicidal ideation and attempts would be associated with higher lifetime smoking, alcohol, and marijuana use; clinical level of depression; lower self-identification with Christian religion; female sex; and older age.

\section{Method}

\section{Participants}

Cross-sectional data were collected among 1005 college students, aged 17 to 24 years $(M=19.19, \mathrm{SD}=1.99)$. Most participants $(97 \%)$ were Ukrainian while others selfidentified as being of Russian, Belarus, Jewish, Armenian, Hungarian, Tatar, or Romanian descent. One-third (31\%) of the participants were males and $69 \%$ were females.

Eighty-nine percent were single, $10 \%$ were married, and $1 \%$ were divorced or widowed. Twenty-one percent had a job that paid on average \$32 per month. Ninety-one percent were debt-free, and $93 \%$ answered that they would not accrue student loans by the time they receive their degree.

Twenty-six percent of the students reported thinking about committing suicide, and $5.45 \%$ had attempted to kill themselves at some point in their life (see Table 1). The rate of suicidal ideation was $17.5 \%$ among 17 - to 18-year-old participants, $29.5 \%$ among 19 - to 20 -year-old participants, $41.4 \%$ among 21 - to 22-year-old participants, and $50.9 \%$ among 23 - to 24 -yearold participants (Fig. 1).

Seventy-nine percent reported lifetime alcohol use, $61 \%$ used tobacco products, and $19 \%$ used marijuana. In this sample, $27.32 \%$ had depression symptoms that warranted clinical attention.

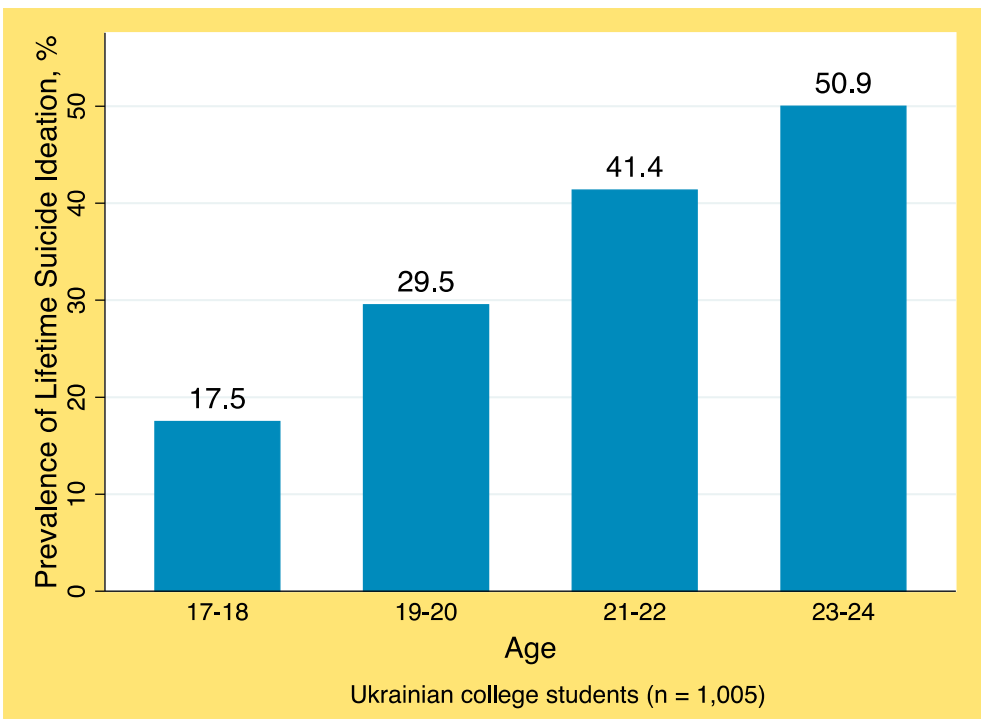

Fig. 1 Suicidal ideation by age among Ukrainian college students 
Table 1 Psychometric properties of the major study variables $(N=1005)$

\begin{tabular}{lr}
\hline Variables & $\%$ \\
\hline Lifetime suicide ideation & 26.13 \\
Females & 30.65 \\
Males & 16.45 \\
Lifetime suicide attempt & 5.45 \\
Females & 6.03 \\
Males & 3.95 \\
Lifetime tobacco use & 60.66 \\
Lifetime alcohol use & 79.38 \\
Lifetime marijuana use & 19.42 \\
Christian & 72.29 \\
Depression (met clinical cut-off level) & 27.32 \\
Female sex & 68.56 \\
Age & \\
17-18 years old & 49.15 \\
19-20 years old & 30.05 \\
21-22 years old & 17.21 \\
23-24 years old & 3.58 \\
\hline
\end{tabular}

\section{Procedure}

Sampling approach entailed inclusion of major universities from Western, Central, Southern, and Eastern Ukraine. Students were invited to participate in the study via announcements and personal invitations at 10 out of 802 Ukrainian universities (Liga Business Information Agency 2016). The present study was part of a larger study that aimed to examine factors associated with the students' early childhood experiences, quality of relationships, mental health, and substance use (Burlaka et al. 2020). The study was approved by the Committee of Ethics and Deontology of the Ukrainian National Academy of Medical Sciences Institute of Neurology, Psychiatry, and Narcology. Students who agreed to participate were provided with a link to survey; they signed the informed consent forms and answered survey questions at home, in classrooms and labs with Internet access using a public or private computer or tablet. The data were collected to a secure online server to increase confidentiality, prevent human error inherent in the manual data entry, avoid distribution costs, increase the speed of completion, avoid data storage costs, incorporate complex skip patterns, prevent incorrect responses and skipped questions, and track response time (Shapiro et al. 2004). None of the students received any compensation and the data collection was managed by faculty members.

The participants were undergraduate and graduate students who attended programs in social work, psychology, special education to philosophy, law, sociology, criminology, cybersecurity, and medicine. They represented all regions (oblasts) of Ukraine. The length of the data collection sessions was about $1 \mathrm{~h}$ and the participants responded to questions about mental health, and substance use, and other life experiences. All measures used in this study were translated from English to Ukrainian and then back-translated into English. In the next step, all items were reviewed and approved by the Ukrainian and U.S. researchers involved in the study. Students answered questions in the Ukrainian language. 


\section{Measures}

Participants responded to a questionnaire that measured sociodemographic characteristics, including sex and age (in years).

\section{Suicidal Behaviors}

Two questions from the National Survey on Drug Use and Health (NSDUH) were used to measure suicidal behaviors in this sample. The first question asked whether participants have ever thought about committing suicide (yes/no). The second question asked whether the participants have ever attempted suicide (yes/no).

\section{Religion}

Participants were asked about their religious affiliation. A majority reported practicing Christianity $(69.41 \%)$ and other religions (3.64\%), while $26.95 \%$ indicated being non-religious. The proportion of participants that had "other" religious affiliations mainly included students who practiced Judaism or self-identified as Muslim. Because this group was not homogenous and relatively small, we excluded it from further analyses and kept participants who were either Christian or non-religious.

\section{Depression}

The Center for Epidemiologic Studies Depression Scale-Revised (CESD-R-10; Björgvinsson et al. 2013; Radloff 1977) was used to measure depression in this sample. This self-reported measure consists of ten items such as "I was bothered by things that usually don't bother me," "My sleep was restless," and "I felt depressed" with response options ranging from 0 ("Rarely or None of the Time") to 3 ("Most or All of the Time"). The measure has previously demonstrated strong psychometric properties (Cronbach's $\alpha=.89$ ) with the recommended cutoff score of 10 (Andresen et al. 1994; Björgvinsson et al. 2013). The full CESD scale has been previously used to study depression among Ukrainian mothers $(\alpha=.89$; Burlaka et al. 2017b). In our study, the Cronbach's $\alpha$ was .84 .

\section{Substance Use}

The Alcohol, Smoking and Substance Involvement Screening Test (ASSIST; WHO Assist Working Group 2002) was developed for the World Health Organization to examine substance use and associated problems. In this study, we focused on lifetime involvement with tobacco, alcohol, and marijuana. The participants answered (yes or no) to the following question, "In your life, which of the following substances have you ever used?" with the following options: "Tobacco products (cigarettes, chewing tobacco, cigars, etc.)," "Alcoholic beverages (beer, wine, spirits, etc.)," and "Cannabis (marijuana, pot, grass, hash, etc.)."

All analyses were conducted in Stata 14.2 statistical software (StataCorp 2015). We used logistic regression, which allows estimation of odds ratios (OR) and $95 \%$ confidence intervals (CI). The outcome variables were suicidal thoughts and suicide attempts. A set of predictors including lifetime use of tobacco products, alcohol, and marijuana; being Christian; sex; and 
Table 2 Logistic regressions predicting lifetime suicidal ideation among Ukrainian college students $(N=1005)$

\begin{tabular}{|c|c|c|c|c|}
\hline \multirow[t]{2}{*}{ Characteristic } & \multicolumn{2}{|l|}{ Bivariate } & \multicolumn{2}{|l|}{ Multivariate } \\
\hline & OR $(95 \% \mathrm{CI})$ & Wald $\chi^{2}$ & $\mathrm{aOR}(95 \% \mathrm{CI})$ & Wald $\chi^{2}$ \\
\hline Tobacco use & $1.18(1.06-1.31)$ & $9.94 * *$ & $0.96(0.65-1.44)$ & 0.05 \\
\hline Alcohol use & $1.47(1.26-1.71)$ & $24.85 * * *$ & $2.08(1.20-3.61)$ & $6.83 * *$ \\
\hline Marijuana use & $1.40(1.25-1.57)$ & $34.64 * * *$ & $2.02(1.32-3.08)$ & $10.62 * * *$ \\
\hline Clinically depressed & $5.76(4.19-7.91)$ & $116.23 * * *$ & $5.21(3.68-7.37)$ & $86.49 * * *$ \\
\hline Christian & $0.59(0.43-0.81)$ & $10.68 * *$ & $0.53(0.37-0.78)$ & $10.89 * *$ \\
\hline Sex (male) & $0.45(0.32-0.63)$ & $20.95 * * *$ & $0.57(0.38-0.87)$ & $6.77 * *$ \\
\hline Age & $1.40(1.28-1.53)$ & $51.83 * * *$ & $1.25(1.12-1.39)$ & $16.73 * * *$ \\
\hline
\end{tabular}

$O R$ odds ratio, $a O R$ adjusted odds ratio, $C I$ confidence interval

$* p<0.05, * * p<0.01, * * * p<0.001$

age were tested in bivariate and multivariate models to understand the individual as well as concurrent associations with suicidal behaviors.

\section{Results}

Table 2 presents the results of the logistic regressions predicting the lifetime suicidal ideation among Ukrainian college students.

We included both unadjusted and adjusted ORs to demonstrate the attenuation effect associated with the presence of confounding variables in the model. Except for tobacco use, all predictor variables that had statistically significant associations with the suicide ideation in the unadjusted model remained significant in the model adjusted for other variables. Being in the clinical range of depression increased the odds of suicide ideation by 5.21 times $(95 \% \mathrm{CI}$ : 3.68-7.37). Students who used alcohol (aOR: 2.08, 95\% CI: 1.20-3.61) and marijuana (aOR: 2.02, 95\% CI: $1.32-3.08)$ were more likely to think about committing suicide. Likewise, women (aOR: .57, 95\% CI: .38-.87) and older students (aOR: 1.25, 95\% CI: 1.12-1.39) reported higher suicidal ideation. In contrast, students who self-identified as Christians had $47 \%$ lower odds of thinking about killing themselves (aOR: 0.53, 95\% CI: $0.37-0.78$ ).

Table 3 Logistic regressions predicting lifetime suicide attempt among Ukrainian college students $(N=1005)$

\begin{tabular}{|c|c|c|c|c|}
\hline \multirow[t]{2}{*}{ Characteristic } & \multicolumn{2}{|l|}{ Bivariate } & \multicolumn{2}{|l|}{ Multivariate } \\
\hline & OR $(95 \% \mathrm{CI})$ & Wald $\chi^{2}$ & aOR $(95 \% \mathrm{CI})$ & Wald $\chi^{2}$ \\
\hline Tobacco use & $1.15(0.94-1.40)$ & 1.82 & $0.80(0.38-1.69)$ & 0.35 \\
\hline Alcohol use & $1.29(0.96-1.72)$ & 2.93 & $1.45(0.54-3.88)$ & 0.53 \\
\hline Marijuana use & $1.42(1.16-1.72)$ & $12.23 * * *$ & $2.22(1.08-4.55)$ & $4.71 *$ \\
\hline Clinically depressed & $3.52(1.99-6.23)$ & $18.62 * * *$ & $3.13(1.67-5.85)$ & $12.67 * * *$ \\
\hline Christian & $0.40(0.22-0.72)$ & $9.27 * *$ & $0.39(0.21-0.74)$ & $8.24 * *$ \\
\hline Sex (male) & $0.64(0.33-1.24)$ & 1.74 & $0.72(0.35-1.51)$ & 0.76 \\
\hline Age & $1.15(.97-1.35)$ & 2.69 & $1.05(0.86-1.28)$ & 0.21 \\
\hline
\end{tabular}

$O R$ odds ratio, $a O R$ adjusted odds ratio, $C I$ confidence interval

${ }^{*} p<0.05, * * p<0.01, * * * p<0.001$ 
The logistic regression predicting lifetime suicide attempts (see Table 3) suggests that those students who reported clinical levels of depression had 313\% (aOR: 3.13, 95\% CI: 1.67-5.85) higher odds of attempting suicide than those who did not meet a clinical cut-off for depressive symptoms. Furthermore, students who reported trying marijuana during their lifetime had $220 \%$ higher odds of attempting suicide (aOR: 2.22, 95\% CI: 1.08-4.55). Finally, compared to students who reported no religious affiliation, students reporting Christian religious affiliation had $61 \%$ lower odds of attempting suicide (aOR: 0.39, 95\% CI: $0.21-0.74$ ). The lifetime use of tobacco products and alcohol as well as sex and age were not associated with the risk of attempting suicide.

\section{Discussion}

Results from this study contribute to the scarce literature on suicidal behaviors in Ukraine. In the present study with college students, the prevalence of suicide ideation was three times higher and the prevalence of suicide attempts was two times higher than in the 2002 Ukrainian national sample from Bromet et al. (2007) study. Traumatic events have been linked with increased suicidality in previous research (e.g., Abdeen et al. 2018). Several political crises have taken place in Ukraine since 2002, including the Orange Revolution of 2004, the Revolution of Dignity of 2014, and ongoing military conflict in Eastern Ukraine (Burlaka et al. 2018). Although not tested in this study, such events could have possibly contributed to a sense of instability, suffering, loss, and hopelessness among Ukrainian young adults who at some point considered or even tried ending their life.

Among the substance use correlates, alcohol and marijuana use have been significantly associated with the increased odds of suicide ideation. Furthermore, marijuana use was associated with suicide attempts in this sample. Tobacco use had the weakest association with suicidal behaviors and was only significantly associated with suicidal ideation in the bivariate model. These findings differ from previous research that used very large U.S. samples (Bohnert et al. 2014; Kessler et al. 2009). Our findings are consistent with the previous research in Ukraine in that smoking was not found to be associated with suicidal ideation (Bromet et al. 2007), and the hypothesized relationship between tobacco use and increased risk for suicide attempts was not supported by these data.

Our results are consistent with prior research linking alcohol with higher suicidal ideation among young adults (Gonzalez et al. 2009; Kim and Burlaka 2018) but differ from previous research linking alcohol use with suicide attempt (Kim and Burlaka 2018; McManama O'Brien et al. 2014). Early alcohol abuse is associated with externalizing psychopathology and higher peer drinking (Burlaka 2017) while spirituality is a protective factor against drinking in Ukraine (Churakova et al. 2017). Cannabis use had significant associations with both suicidal ideation and attempt among Ukrainian students. This finding is consistent with prior research on the impact of cannabis on suicidal behaviors in South America, Africa, Asia (Carvalho et al. 2019; Pereira-Morales et al. 2017), and the United States (Delforterie et al. 2015), but differs from a study with Turkish young adults in which cannabis use was associated with self-harm but not with suicidal ideation or attempt (Toprak et al. 2011).

The ongoing debate primarily focuses on the benefits of legalizing marijuana use in Ukraine (Interfax-Ukraine 2017) offering little information on potential risks associated with cannabis use. Although the present study has not addressed the potential benefits from cannabis use, these data provide a clear indication of increased suicidal risks even when controlling for the 
use of other substances and depression. As such, these results can be useful in the development of national policy and designing drug prevention programs with early adult populations.

Consistent with previous research (Ribeiro et al. 2018), clinical depression had the strongest association with suicidal ideation and attempt in this study. Feeling depressed and hopeless appears to increase the risk of suicide among Ukrainian college students. Previous research found Ukrainian students coping with psychological difficulties primarily relied on self-help, support from friends and family, and substance use (Burlaka et al. 2014b) in the absence of high-quality mental health services (Burlaka et al. 2014a). Given the present findings that increased depressive symptoms are associated with higher suicidal risks, it is crucial to improve the mental health services in Ukraine.

Consistent with prior literature (Dervic et al. 2004), our results suggest that students who selfidentified as Christians had significantly lower odds of reporting suicide ideation or suicide attempt. Ancestors of modern Ukrainians, Belarusians, and Russians were converted to Christianity by Grand Prince Volodymyr in 989 in the capital of present-day Ukraine, Kyiv (Herlihy 1994). During the Communist regime, the freedom to exercise religion and culture was largely restricted for Ukrainian people (Burlaka et al. 2018). After the collapse of the Soviet Union, the role of religion has increased both in the public sphere and in private life (Titarenko 2008). Ukrainian Orthodox Christian church does not see suicide as such that results from illness and interprets it as a sin against God's gift of life resulting in a ban for cemetery burials for people who have taken their life (Kononenko 2018). In addition to being cautioned that killing self is an unacceptable act, many Christians enjoy the benefits of fellowship and mutual support that can be accessed through church participation, believe in the idea of an afterlife, and are more hopeful (Stack 2013). The findings from this study suggest that Christianity is an important protective mechanism against suicidal behaviors among young Ukrainian adults attending colleges.

The present study found that older students had a higher risk of suicidal ideation. Previously, Bromet et al. (2007) reported that the average onset age of suicidal behaviors in Ukraine was 31 years. Using the longitudinal data, Fergusson et al. (2000) reported that $28.8 \%$ of participants had thought about committing suicide by the age of 21 years. Our findings were similar to those by Fergusson et al. (2000) in that $96 \%$ percent of our study participants were 22 years of age or younger and the prevalence of lifetime suicidal ideation was $26.13 \%$. Additional research needs to identify reasons that would explain why older Ukrainians have more suicidal behaviors. We believe younger Ukrainians might feel more optimistic about their future but as they grow older, they become more disillusioned and hopeless facing neverending political and economic struggles in their country (Burlaka et al. 2018).

In the present study, women were more likely to think about suicide than men. Our results are consistent with the findings from a U.S. study with 18- to 25-year-old young adults in which Kim and Burlaka et al. (2018) found that women had a higher risk of suicidal behaviors. Our results were also consistent with Langhinrichsen-Rohling et al. (2009) study who reported higher rates of suicidal ideation and attempts among women. Likewise, in the earlier research in Ukraine, women had significantly higher odds of suicidal ideation (Bromet et al. 2007). However, similar to Bromet et al. (2007), our study did not find a significant association between female sex and suicide attempt.

Together, these results highlight a need to develop effective, culturally appropriate, and accessible mental health services for Ukrainian college students (Burlaka et al. 2014a; Burlaka et al. 2014b). Effective interventions that could be implemented on campuses across Ukraine are cognitive-behavioral therapy, interpersonal psychotherapy, dialectical behavior therapy, outreach interventions, and problem-solving therapy (Comtois and Linehan 2006). Ukrainian 
students at-risk for suicide may benefit from enhancing emotion regulation skills and developing distress tolerance skills (McCauley et al. 2018). Effective prevention interventions need to achieve change in symptoms, improve the functional capacity of individuals, should not be costly, and should be easy to teach and use (Hollon et al. 2002).

\section{Limitations and Implications for Future Research}

The present results must be interpreted in light of several limitations. First, the study used a convenience, cross-sectional sample which might limit the ability to generalize the results and draw causal conclusions. It is also possible that student populations may experience different rates of suicidal behaviors compared to young adults who were unable or unwilling to receive higher education. Perhaps, being in college can create additional stress on young people and increase suicidal risk. Alternatively, being a student may instill a sense of hope about better opportunities and quality of life in the future and thus buffer suicidality. It is also possible that some students were not fully forthcoming when answering potentially sensitive questions about suicidal behaviors and substance use. Hence, as with most studies examining such topics, the reported rates may have been underestimated.

Next, additional research is needed to understand the trajectories of suicidal behaviors beyond the emerging adulthood age. It is critical to understand whether suicidal behaviors decrease after students graduate from universities. Does the Ukrainian higher education system prepare students well enough for gainful employment? How does increased income impact the rate of suicidality? These and other similar questions could be addressed in the samples of recent college graduates.

Notwithstanding the limitations, the present study has used a large sample of students representing all regions of Ukraine. Ukraine is one of the largest countries in Europe but remains to be heavily understudied. Our findings shed light on the relationship between substance use, mental health risk factors, and religious involvement and suicidal behaviors in a sample of young adults. These results can be particularly useful for policy making and programming for emerging adults in Ukraine and other post-Communist countries that share a political, cultural, and socio-economic backgrounds with Ukraine.

\section{Compliance with Ethical Standards}

Conflict of Interest The authors declare that they have no conflict of interest.

Ethical Approval The study was approved by the Committee of Ethics and Deontology of the Ukrainian National Academy of Medical Sciences Institute of Neurology, Psychiatry, and Narcology. Before completing the survey, participants were informed about the study and gave their consent. All procedures performed in this study involving human participants were in accordance with the institutional and national ethical standards and with the 1964 Helsinki declaration and its later amendments.

\section{References}

Abdeen, Z., Brunstein-Klomek, A., Nakash, O., Shibli, N., Nagar, M., Agha, H., Hallaq, S., Kanat-Maymon, Y., Juerges, H., Levav, I., \& Qasrawi, R. (2018). The association between political violence and the connection between bullying and suicidality among palestinian youth. Suicide and Life-threatening Behavior, 48(1), 95-104. https://doi.org/10.1111/sltb.12338. 
Agarkova, A. I. (2017). Propensity for depression as a factor for suicidal behaviors among student youths. Herald of Skovoroda Kharkiv National Pedagogical University, 56, 19-29. https://doi.org/10.5281/zenodo.888332.

Andresen, E. M., Malmgren, J. A., Carter, W. B., \& Patrick, D. L. (1994). Screening for depression in well older adults: evaluation of a short form of the CES-D. American Journal of Preventive Medicine, 10(2), 77-84. https://doi.org/10.1016/S0749-3797(18)30622-6.

Aradilla-Herrero, A., Tomás-Sábado, J., \& Gómez-Benito, J. (2014). Associations between emotional intelligence, depression and suicide risk in nursing students. Nurse Education Today, 34(4), 520-525. https:/doi. org/10.1016/j.nedt.2013.07.001.

Arria, A. M., O’Grady, K. E., Caldeira, K. M., Vincent, K. B., Wilcox, H. C., \& Wish, E. D. (2009). Suicide ideation among college students: a multivariate analysis. Archives of Suicide Research : Official Journal of the International Academy for Suicide Research, 13(3), 230-246. https://doi.org/10.1080 /13811110903044351.

Bacherikov, A. M., Matuzok, E. G., Kharina, K. V., Sitenko, L. M., Horbunov, O. V., \& Kis, A. V. (2007). Completed suicide attempts committed under the influence of alcohol. Ukrainian Bulletin of Psychoneurology, 15(54), 69.

Bacherikov, A. M., Kuzminov, V. N., \& Tkachenko, T. V. (2012). Mechanisms of development of suicidal behaviors among alcohol dependent patients. Ukrainian Bulletin of Psychoneurology, 20(72), 161.

Björgvinsson, T., Kertz, S. J., Bigda-Peyton, J. S., McCoy, K. L., \& Aderka, I. M. (2013). Psychometric properties of the CES-D-10 in a psychiatric sample. Assessment, 20(4), 429-436. https://doi.org/10.1177 $/ 1073191113481998$.

Bohnert, K. M., Ilgen, M. A., McCarthy, J. F., Ignacio, R. V., Blow, F. C., \& Katz, I. R. (2014). Tobacco use disorder and the risk of suicide mortality. Addiction, 109(1), 155-162. https://doi.org/10.1111/add.12381.

Borges, G., Nock, M. K., Haro Abad, J. M., Hwang, I., Sampson, N. A., Alonso, J., Andrade, L. H., Angermeyer, M. C., Beautrais, A., Bromet, E., Bruffaerts, R., de Girolamo, G., Florescu, S., Gureje, O., Hu, C., Karam, E. G., Kovess-Masfety, V., Lee, S., Levinson, D., Medina-Mora, M. E., Ormel, J., Posada-Villa, J., Sagar, R., Tomov, T., Uda, H., Williams, D. R., \& Kessler, R. C. (2010). Twelve-month prevalence of and risk factors for suicide attempts in the World Health Organization World Mental Health Surveys. The Journal of Clinical Psychiatry, 71(12), 1617-1628. https://doi.org/10.4088/JCP.08m04967blu.

Bromet, E. J., Havenaar, J. M., Tintle, N., Kostyuchenko, S., Kotov, R., \& Gluzman, S. (2007). Suicide ideation, plans and attempts in Ukraine: Findings from the Ukraine World Mental Health Survey. Psychological Medicine, 37(6), 807-819. https://doi.org/10.1017/S0033291707009981.

Burlaka, V. (2016). Externalizing behaviors of Ukrainian children: the role of parenting. Child Abuse \& Neglect, 54, 23-32. https://doi.org/10.1016/j.chiabu.2015.12.013.

Burlaka, V. (2017). Effects of individual, peer, and family factors on child alcohol abuse in Ukraine. Journal of Child and Family Studies, 26(7), 1780-1789. https://doi.org/10.1007/s10826-017-0718-4.

Burlaka, V., Churakova, I., Aavik, O. A., \& Goldstein, D. (2014a). Perceived barriers to mental health services: a mixed-method study with Ukrainian college students. European Journal of Higher Education, 4(2), 167183. https://doi.org/10.1080/21568235.2014.890524.

Burlaka, V., Churakova, I., Aavik, O. A., Staller, K. M., \& Delva, J. (2014b). Attitudes toward health-seeking behaviors of college students in Ukraine. International Journal of Mental Health and Addiction, 12(5), 549560. https://doi.org/10.1007/s11469-014-9483-4.

Burlaka, V., Graham-Bermann, S. A., \& Delva, J. (2017a). Family factors and parenting in Ukraine. Child Abuse \& Neglect, 72, 154-162. https://doi.org/10.1016/j.chiabu.2017.08.007.

Burlaka, V., Kim, Y. J., Crutchfield, J. M., Lefmann, T. A., \& Kay, E. S. (2017b). Predictors of internalizing behaviors in Ukrainian children. Family Relations, 66, 854-866. https://doi.org/10.1111/fare.12289.

Burlaka, V., Serdiuk, O., Nickelsen, T., Tkach, B., \& Khvorova, H. (2018). Family life education in Ukraine. In M. Robila \& A. C. Taylor (Eds.), Global perspectives on family life education. Springer International Publishing AG.

Burlaka, V., Hong, J. S., Churakova, I., Serdiuk, O., Proskura, V., \& Shvets, D. (2020). The role of adverse childhood experiences and corporal punishment in early adulthood depression and substance use among Ukrainian college students. Journal of Family Violence., 35, 285-295. https://doi.org/10.1007/s10896-01900110-x .

Burlaka, V., Wu, Q., Wu, S., \& Churakova, I. (2019). Internalizing and externalizing behaviors among Ukrainian children: the role of family communication and maternal coping. Journal of Child and Family Studies, 28(5), 1283-1293. https://doi.org/10.1007/s10826-019-01377-w .

Burlaka, V., Kim, Y. J., Lee, N. Y., Kral, M., \& Hong, J. S. (in press). Suicidal behaviors among college students at a Bible belt university: the role of childhood trauma, spirituality, anxiety and depression. Best Practices in Mental Health.

Carvalho, A. F., Stubbs, B., Vancampfort, D., Kloiber, S., Maes, M., Firth, J., Kurdyak, P. A., Stein, D. J., Rehm, J., \& Koyanagi, A. (2019). Cannabis use and suicide attempts among 86,254 adolescents aged 12-15 years 
from 21 low- and middle-income countries. European Psychiatry, 56, 8-13. https://doi.org/10.1016/j. eurpsy.2018.10.006.

Centers for Disease Control and Prevention. (2019). WISQARS. Leading causes of death reports, 1981-2017. https://webappa.cdc.gov/sasweb/ncipc/leadcause.html. Accessed 20 Nov 2019.

Cheong, K.-S., Choi, M.-H., Cho, B.-M., Yoon, T.-H., Kim, C.-H., Kim, Y.-M., \& Hwang, I.-K. (2012). Suicide rate differences by sex, age, and urbanicity, and related regional factors in Korea. Journal of Preventive Medicine and Public Health, 45(2), 70-77. https://doi.org/10.3961/jpmph.2012.45.2.70.

Churakova, I., Burlaka, V., \& Parker, T. W. (2017). Relationship between alcohol use, spirituality and coping. International Journal of Mental Health and Addiction, 15(4), 842-852. https://doi.org/10.1007/s11469-0179759-6.

Churakova, I., Burlaka, V., Crutchfield, J., Lee, N. Y., Fisher, A., Kim, Y. J., Zhang, S., \& Nepal, J. (2020). Unpacking the Mississippi blues: relationship between internalizing problems and health behaviors. International Social Work., 002087282090831. https://doi.org/10.1177/0020872820908319.

Comtois, K. A., \& Linehan, M. M. (2006). Psychosocial treatments of suicidal behaviors: a practice-friendly review. Journal of Clinical Psychology, 62(2), 161-170. https://doi.org/10.1002/jclp.20220.

Curtin, S. C., Warner, M. W., \& Hedegaard, H. (2016). Increase in suicide in the United States, 1999-2014. NCHS Data Brief (no. 241). National Center for Health Statistics.

Delforterie, M. J., Lynskey, M., Huizink, A. C., Creemers, H. E., Grant, J. D., Few, L. R., Glowinski, A. L., Statham, D. J., Trull, T. J., Bucholz, K. K., Madden, P. A. F., Martin, N. G., Heath, A. C., \& Agrawal, A. (2015). The relationship between cannabis involvement and suicidal thoughts and behaviors. Drug and Alcohol Dependence, 150, 98-104. https://doi.org/10.1016/j.drugalcdep.2015.02.019.

Dervic, K., Oquendo, M. A., Grunebaum, M. F., Ellis, S., Burke, A. K., \& Mann, J. J. (2004). Religious affiliation and suicide attempt. American Journal of Psychiatry, 161(12), 2303-2308. https://doi. org/10.1176/appi.ajp.161.12.2303.

Eisenberg, D., Gollust, S. E., Golberstein, E., \& Hefner, J. L. (2007). Prevalence and correlates of depression, anxiety, and suicidality among university students. American Journal of Orthopsychiatry, 77(4), 534-542.

Fan, A. P., Kosik, R. O., Mandell, G. A., Tran, D. T. P., Cheng, H. M., Chen, C. H., Su, T.-P., \& Chiu, A. W. (2012). Suicidal ideation in medical students: who is at risk? Annals of the Academy of Medicine-Singapore, $41(9), 377$.

Fergusson, D. M., Woodward, L. J., \& Horwood, L. J. (2000). Risk factors and life processes associated with the onset of suicidal behaviour during adolescence and early adulthood. Psychological Medicine, 30(1), 23-39. https://doi.org/10.1017/S003329179900135X.

Garlow, S. J., Rosenberg, J., Moore, J. D., Haas, A. P., Koestner, B., Hendin, H., \& Nemeroff, C. B. (2008). Depression, desperation, and suicidal ideation in college students: Results from the American Foundation for Suicide Prevention College Screening Project at Emory University. Depression and Anxiety, 25(6), 482488. https://doi.org/10.1002/da.20321.

Gonzalez, V. M., Collins, R. L., \& Bradizza, C. M. (2009). Solitary and social heavy drinking, suicidal ideation, and drinking motives in underage college drinkers. Addictive Behaviors, 34(12), 993-999. https://doi. org/10.1016/j.addbeh.2009.06.001.

Herlihy, P. (1994). Crisis in society and religion in Ukraine. Occasional Papers on Religion in Eastern Europe, $14(2), 1$.

Hollon, S. D., Muñoz, R. F., Barlow, D. H., Beardslee, W. R., Bell, C. C., Bernal, G., Clarke, G. N., Franciosi, L. P., Kazdin, A. E., Kohn, L., Linehan, M. M., Markowitz, J. C., Miklowitz, D. J., Persons, J. B., Niederehe, G., \& Sommers, D. (2002). Psychosocial intervention development for the prevention and treatment of depression: promoting innovation and increasing access. Biological Psychiatry, 52(6), 610-630. https://doi. org/10.1016/S0006-3223(02)01384-7.

Interfax-Ukraine. (2017). Freedom march to decriminalize marijuana for personal use planned in Kyiv: KyivPost-Ukraine's Global Voice. KyivPost. https://www.kyivpost.com/ukraine-politics/freedom-marchdecriminalize-marijuana-personal-use-planned-kyiv.html. Accessed 29 Nov 2019.

Joiner, T. E., \& Rudd, M. D. (2005). Suicide science expanding the boundaries. Kluwer Academic Publishers http://accesbib.uqam.ca/cgi-bin/bduqam/transit.pl?\&noMan=25127668. Accessed 20 Mar 2020.

Kessler, R. C., Borges, G., Sampson, N., Miller, M., \& Nock, M. K. (2009). The association between smoking and subsequent suicide-related outcomes in the National Comorbidity Survey panel sample. Molecular Psychiatry, 14(12), 1132-1142. https://doi.org/10.1038/mp.2008.78.

Kholmogorova, A. B., Garanian, N. G., Gorshkova, D. A., \& Melnyk, A. M. (2009). Suicidal behaviors in a student population. Cultural-Historiacal Psychology, 5(3), 101-110.

Kim, Y. J., \& Burlaka, V. (2018). Gender differences in suicidal behaviors: mediation role of psychological distress between alcohol abuse/dependence and suicidal behaviors. Archives of Suicide Research, 22(3), 405-419. https://doi.org/10.1080/13811118.2017.1355284. 
Kokkevi, A., Richardson, C., Olszewski, D., Matias, J., Monshouwer, K., \& Bjarnason, T. (2012). Multiple substance use and self-reported suicide attempts by adolescents in 16 European countries. European Child \& Adolescent Psychiatry, 21(8), 443-450. https://doi.org/10.1007/s00787-012-0276-7.

Kononenko, N. (2018). Vernacular religion on the prairies: negotiating a place for the unquiet dead. Canadian Slavonic Papers, 60(1-2), 108-135. https://doi.org/10.1080/00085006.2018.1446242.

Kovacs, M., \& Garrison, B. (1985). Hopelessness and eventual suicide: a 10-year prospective study of patients hospitalized with suicidal ideation. American Journal of Psychiatry, 1(42), 559-563.

Langhinrichsen-Rohling, J., Friend, J., \& Powell, A. (2009). Adolescent suicide, gender, and culture: a rate and risk factor analysis. Aggression and Violent Behavior, 14(5), 402-414. https://doi.org/10.1016/j. avb.2009.06.010.

Liga Business Information Agency. (2016). The Ministry of Education to shut down 10 more universities. Ukrainska Pravda. http://pda.pravda.com.ua/news/id_7100764/. Accessed 20 Mar 2020.

McCauley, E., Berk, M. S., Asarnow, J. R., Adrian, M., Cohen, J., Korslund, K., Avina, C., Hughes, J., Harned, M., Gallop, R., \& Linehan, M. M. (2018). Efficacy of dialectical behavior therapy for adolescents at high risk for suicide: a randomized clinical trial. JAMA Psychiatry, 75(8), 777-785. https://doi.org/10.1001 /jamapsychiatry.2018.1109.

McManama O’Brien, K. H., Becker, S. J., Spirito, A., Simon, V., \& Prinstein, M. J. (2014). Differentiating adolescent suicide attempters from ideators: examining the interaction between depression severity and alcohol use. Suicide and Life-threatening Behavior, 44(1), 23-33. https://doi.org/10.1111/sltb.12050.

Melissa-Halikiopoulou, C., Tsiga, E., Khachatryan, R., \& Papazisis, G. (2011). Suicidality and depressive symptoms among nursing students in northern Greece. Health Science Journal, 5(2), 90-97.

Moran, P., Coffey, C., Romaniuk, H., Olsson, C., Borschmann, R., Carlin, J. B., \& Patton, G. C. (2012). The natural history of self-harm from adolescence to young adulthood: a population-based cohort study. The Lancet, 379(9812), 236-243. https://doi.org/10.1016/S0140-6736(11)61141-0.

Nock, M. K., Hwang, I., Sampson, N., Kessler, R. C., Angermeyer, M., Beautrais, A., Borges, G., Bromet, E., Bruffaerts, R., \& De Girolamo, G. (2009). Cross-national analysis of the associations among mental disorders and suicidal behavior: findings from the WHO World Mental Health Surveys. PLoS Medicine, 6(8), e1000123. https://doi.org/10.1371/journal.pmed.1000123.

Nock, M. K., Green, J. G., Hwang, I., McLaughlin, K. A., Sampson, N. A., Zaslavsky, A. M., \& Kessler, R. C. (2013). Prevalence, correlates, and treatment of lifetime suicidal behavior among adolescents: results from the National Comorbidity Survey Replication Adolescent Supplement. JAMA Psychiatry, 70(3), 300-310. https://doi.org/10.1001/2013.jamapsychiatry.55.

Norko, M. A., Freeman, D., Phillips, J., Hunter, W., Lewis, R., \& Viswanathan, R. (2017). Can religion protect against suicide? The Journal of Nervous and Mental Disease, 205(1), 9-14. https://doi.org/10.1097 /NMD.0000000000000615.

Pereira-Morales, A. J., Adan, A., Camargo, A., \& Forero, D. A. (2017). Substance use and suicide risk in a sample of young Colombian adults: an exploration of psychosocial factors: substance use and suicide risk in young colombian adults. The American Journal on Addictions, 26(4), 388-394. https://doi.org/10.1111 lajad.12552.

Pescosolido, B. A. (1990). The social context of religious integration and suicide: pursuing the network explanation. The Sociological Quarterly, 31(3), 337-357. https://doi.org/10.1111/j.1533-8525.1990. tb00332.x.

Piliahina, H. I., \& Chumak, S. A. (2014). Predictors of development and recidivism of self-harming behaviors. Suicidology, 5(2(15)).

Piliahina, G. i., Sementsul, V. E., \& Chumak, S. A. (2008). Existential crisis as a psychopathological basis of suicidality. Ukrainian Bulletin of Psychoneurology, 16(1(54)).

Radloff, L. S. (1977). The CES-D scale a self-report depression scale for research in the general population. Applied Psychological Measurement, 1(3), 385-401.

Rakhimkulova, A. S. (2016). Relationship between risky and suicidal behaviors among adolescents in Ukraine (Kamianets-Podilskyi Ohienko National University and Kostiuk Institute of Psychology, Vol. 34). Aksioma.

Ribeiro, J. D., Huang, X., Fox, K. R., \& Franklin, J. C. (2018). Depression and hopelessness as risk factors for suicide ideation, attempts and death: meta-analysis of longitudinal studies. The British Journal of Psychiatry, 212(5), 279-286. https://doi.org/10.1192/bjp.2018.27.

Shapiro, J. S., Bessette, M. J., Baumlin, K. M., Ragin, D. F., \& Richardson, L. D. (2004). Automating research data collection. Academic Emergency Medicine, 11(11), 1223-1228. https://doi.org/10.1197/j. aem.2004.08.017.

Stack, S. (2013). Religion and suicide acceptability: a review and extension. Suicidologi, 18(1), 3-9. https://oi. org/10.5617/suicidologi.2181.

StataCorp. (2015). Stata statistical software: Release Stata/MP 14.2. StataCorp LP. 
Titarenko, L. (2008). On the shifting nature of religion during the ongoing post-communist transformation in Russia, Belarus and Ukraine. Social Compass, 55(2), 237-254. https://doi.org/10.1177/0037768607089743.

Toprak, S., Cetin, I., Guven, T., Can, G., \& Demircan, C. (2011). Self-harm, suicidal ideation and suicide attempts among college students. Psychiatry Research, 187(1), 140-144. https://doi.org/10.1016/j. psychres.2010.09.009.

UkrStat. (2017). Natural movement of population in 2016. State Statistic Service of Ukraine http://database. ukrcensus.gov.ua/PXWEB2007/ukr/publ_new1/2017/BL1001_2017_01_nat.pdf. Accessed 26 Oct 2019.

VanderWeele, T. J., Li, S., Tsai, A. C., \& Kawachi, I. (2016). Association between religious service attendance and lower suicide rates among US women. JAMA Psychiatry, 73(8), 845-851. https://doi.org/10.1001 /jamapsychiatry.2016.1243.

Värnik, A., Kõlves, K., Allik, J., Arensman, E., Aromaa, E., van Audenhove, C., Bouleau, J.-H., van der FeltzCornelis, C. M., Giupponi, G., Gusmão, R., Kopp, M., Marusic, A., Maxwell, M., Óskarsson, H., Palmer, A., Pull, C., Realo, A., Reisch, T., Schmidtke, A., Sola, V. P., Wittenburg, L., \& Hegerl, U. (2009). Gender issues in suicide rates, trends and methods among youths aged 15-24 in 15 European countries. Journal of Affective Disorders, 113(3), 216-226. https://doi.org/10.1016/j.jad.2008.06.004.

WHO. (2016a). Suicide rate estimates, age-standardized-estimates by country. WHO http://apps.who. int/gho/data/node.main.MHSUICIDEASDR?lang=en. Accessed 26 Oct 2019.

WHO. (2016b). World Health Statistics data visualizations dashboard: Suicide. WHO http://apps.who. int/gho/data/node.sdg.3-4-viz-2?lang=en. Accessed 26 Oct 2019.

WHO. (2019). Suicide. https://www.who.int/news-room/fact-sheets/detail/suicide. Accessed 26 Oct 2019.

WHO Assist Working Group. (2002). The Alcohol, Smoking and Substance Involvement Screening Test (ASSIST): development, reliability and feasibility. http://publichealthwell.ie/node/66883. Accessed 26 Oct 2019 .

Publisher's Note Springer Nature remains neutral with regard to jurisdictional claims in published maps and institutional affiliations. 